\title{
A Multilevel Approach to Individual Readiness to Change
}

\author{
David Desplaces \\ University of Hartford
}

\begin{abstract}
This research seeks to expand our understanding of individual readiness to change and its antecedents. Antecedents to change are explored including both the objective and subjective context of change in an effort to clarify their significance and relationship with individual readiness to change and in determining the success of change. A theoretically sound and testable individual readiness model is presented including a brief discussion on how to go about testing each variables of the proposed model.
\end{abstract}

\section{Introduction}

History tells us that organizational change is chaotic (Gleick, 1987) and can be dramatic for both the individual and the organization (Abrahamson, 2000). It can bring about many disruptions and adverse effects. Although some argue that not all changes are necessary (de Jager, 2001), Lewin (1951), later followed by Schein (1996), describes change as a difficult process involving painful unlearning and relearning, as employees attempt to restructure their thoughts, feelings and behaviors with regard to the change at hand. Porras and Robertson's (1992) review of organizational development (OD) literature found that targeted organizational change was attained in only 38 percent of the cases examined, compared to 53 percent of the cases which showed no change, and nine percent of the cases which demonstrated change in opposite directions than intended. Despite these low rates of successful change, practitioners and scholars still use models to direct organizational change efforts.

OD practice focuses mostly on changing the context and processes under which employees in an organization function. The assumption is that their alterations will result in changed employee behaviors in the form of low absenteeism, high performance, and/or low turnover, which will bring about changes in organizational outcomes such as increased revenue, reduction of costs, or improved market share, and/or market position. These models limit change efforts usually by taking single-level approaches that focus on individual, group, or organizational targets only. Furthermore, scholars point that the models themselves are underdeveloped theoretically (Pettigrew, Woodman, \& Cameron, 2001; Porras \& Robertson, 1992).

This research attempts to clarify the role and potential contribution that the antecedents to individual readiness to change may have in change research. Therefore, one of the important contributions of this inquiry is to establish a framework for studying readiness to change by presenting a more comprehensive and testable individual change model.

Specifically in this research, we seek to deepen our understanding of adoption by integrating theories and empirical research in readiness to change, individual readiness 
to change, $\mathrm{OD}$, organizational change, and other literatures to develop a more comprehensive model of individual behavioral change that takes into account dynamics at both the individual (micro) and organizational (macro) level of analysis. By recognize the relationship between objective and subjective work setting changes, and their significance in determining an individual's readiness to adopt change; we propose that work setting changes and individual attitudes towards the change conjointly are set to affect the outcome of the change effort.

\section{Review of the Literature}

\section{Readiness to Change}

In the organizational context, individual readiness to change is defined as the extent to which an individual is prepared to participate in a different organizational activity (Huy, 1999). It is viewed as the precursor to the behaviors of either resistance to, or support for, a change effort undertaken by an organization (Allport, 1967; Armenakis, Harris, \& Mossholder, 1993; Rafferty \& Simons, 2001).

Previous research seems to support that readiness of individuals in an organization to undertake change appears to be a precursor to successful change (Armenakis et al., 1993; Eby, Adams, Russell, \& Gaby, 2000; Edwards, Jumper-Thurman, Plested, Oetting, \& Swanson, 2000; Levesque, Prochaska, \& Prochaska, 1999; Rafferty \& Simons, 2001) and a prerequisite for meeting business objectives in a dynamic environment, it remains understudied and ill explored in organizational contexts where changes are being proposed. The following section reviews the current literature on individual readiness as an attitudinal construct, in an attempt to define the role that the attitude of readiness to change may have in organizational change research and practice.

\section{Individual Readiness to Change as an Attitude}

As an attitude, readiness to change is presented in this research as a field of forces, supporting or resisting change. Those forces must be altered for change to take place. Individual readiness to change reflects the thoughts, feelings and intentions of an individual, which may or may not lead to a particular behavior associated with his/her attitudes. Individual readiness to change, as an attitudinal construct, has just begun to be explored conceptually.

Piderit (2000) attempts to clarify readiness to change as an attitudinal construct by distinctively identifying the three dimensions as cognitive, affective and intentional. These dimensions make up what is also known as the tripartite view of attitudes (Ajzen, 1984; Olson \& Zanna, 1993). It is generally held in the attitude theory literature that an attitude exerts an influence upon the individual's behavioral response to objects and situations an individual faces (Allport, 1967). 
The literature points to the importance of all three dimensions (Ajzen, 1984; Piderit, 2000), the distinctions between them (Ajzen, 1984; Eagly \& Chaiken, 1993), and their potential interactions (Olson \& Zanna, 1993; Piderit, 2000). Furthermore, recent research empirically tested individual readiness as an attitude (Desplaces \& Beauvais, 2004) and as a predisposition (Oreg, 2003). However, an attitude toward change can better be understood when examined in relation to the change context being implemented (Pettigrew et al., 2001; Van de Ven \& Poole, 2002). Therefore, it can be argued that change in the context gives rise to one's attitudinal predisposition to change. Such contexts may include organizational context, perceived support for the change and perceived membership readiness to adopt change. We now turn our attention to a discussion of possible antecedents to an individual's readiness to change.

\section{The Antecedents of Individual Readiness to Change}

The previous sections of this manuscript establish the importance of assessing and understanding individuals' attitudes about change and point to the limited contributions of studies about individual readiness to change in the context of change have been made thus far. Therefore, it appears that previous theories and models of individual change have not focused on specifically linking individual readiness to adopt technologically based changes, perceptions of work setting changes, and subjective perceptions of organizational support and norms for change.

The present research offers a testable approach to understanding individual readiness to adopt change in the work place. It speculates that employees derive meaning from their subjective perceptions of what is happening in their organizational situation. Individuals' perceptions of organizational support for changes and of organization membership readiness to change affect personal readiness to change. Self-efficacy is posited to moderate the relationship between perceived organization support and readiness to change. Therefore, our model predicts that an individual will experience more readiness to change if he/she perceives that the environment supports the change, moderated by one's self-efficacy regarding the required change, and that other organizational members are ready for the changes. It points to the significance of studying individual readiness to change in its context. 
Figure 1

Integrative Approach to Individual Readiness to Change

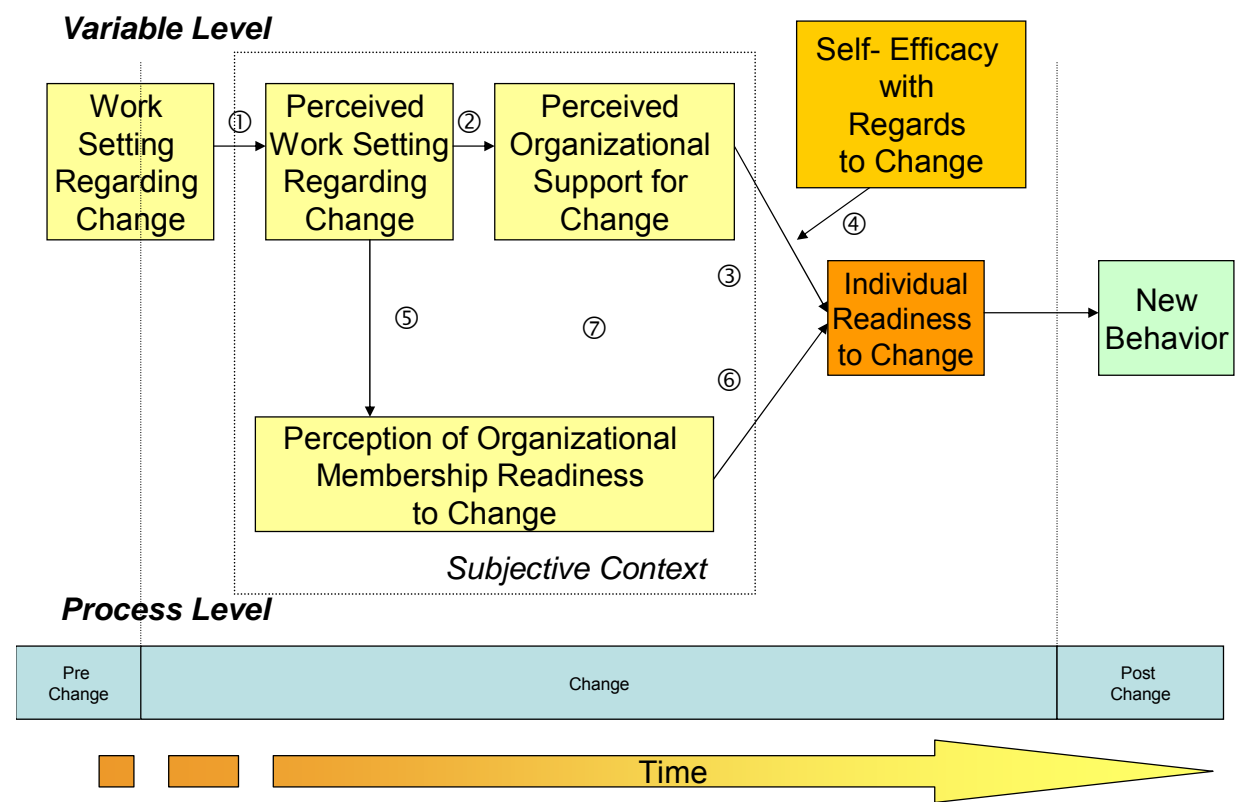

In the next sections, special attention is given to the antecedents of individual readiness to change. That is accomplished through the examination of organizational work setting variables (Porras \& Robertson, 1992), and their links to both perceived organizational support (Eisenberger, Huntington, Hutchison, \& Sowa, 1986) and perceived organizational membership readiness (Eby et al., 2000). These variables are also examined as mediating elements linking organization context to individual readiness to change. In addition, the moderating role of self-efficacy in the relationship between perceived organizational support and individual readiness to change is suggested.

\section{Work setting changes.}

OD is a system-wide set of planned changes that aims to improve an organization's effectiveness. It is the study of "changing" an organization through individual behavioral changes. Emphasis is put on the premise that organizational change comes through collective individual behavioral changes; therefore, individual behavioral changes have organizational consequences. That assumption is at the root of this research, and is also reflected in much of the readiness to change literature (Armenakis \& Bedeian, 1999; Eby et al., 2000).

In changing organizations, OD approaches assume that individual members must $d o$ things differently (i.e., behave differently) for the system to change: thinking and feeling is not enough (Porras et al., 1992). Beer (1987) proclaims that individual behavioral 
change is the crucial link between an organization's intention to change and any organizational outcome. Porras and Robertson's (1992) OD framework acknowledges the importance of behavioral change "as the intermediate factor linking change agent interventions in the work setting and organizational outcomes" (p.726), whereby "the change in the behavior of individual organizational members [is] a prerequisite for meaningful and lasting organizational change" (p. 724).

Porras and Robertson's framework emphasizes the importance of work settings, which encompass more organizational variables than just culture, structure, strategy and processes. They argue that an organization's vision, mediated by four key interrelated organizational factors (i.e., work setting variables), will shape and guide people's cognitions, which in turn will influence their on-the-job behaviors.

The authors speculate that change in work settings, mediated by individual cognitions and member on-the-job behaviors, leads to changes in organizational and individual outcomes. The work setting variables are Organizing Arrangements, Social Factors, Physical Setting and Technology. Porras and Robertson's proposed work setting variables represent the organizational change context, and serve as guiding elements in linking organizational level constructs with individual level readiness to change.

All of the above work-setting factors interact with each other to affect individual cognition, according to the authors. Porras and Robertson (1992) point out that expectancy (Porter \& Lawler, 1968; Vroom, 1964) and social learning theories (Bandura, 1977, 1986, 1997) have established that the environment directly influences an individual's conscious choices about one's behavior, noting "the importance of [the] environment as a source of information about appropriate behaviors"(p. 727). Thus, Porras and Robertson (1992) say that "through natural processes of perception and attribution, individuals form beliefs regarding their organizational environment" (p.727) which then energize, direct and regulate behavior (Bernstein \& Burke, 1989). These processes establish the link between individual cognition and on-the-job behaviors, a link that also has been suggested in the readiness to change literature. Therefore, perceptions of changes in these work setting variables are suggested to be a key determinant of individual attitudes and behaviors related to change.

Although their framework was not fully supported, Porras and Robertson (1992) show that when neither work setting nor individual behavior change occurred, 70 percent of the studies showed no change in desired outcomes. When either work setting or individual behavior change occurred, organizational outcomes changed in 87 percent of the cases.

These findings indicate a link between changes in work settings, individual change and organizational change. However, the inconsistent results indicate that we do not fully understand how these constructs are linked. First, cognitions (e.g., cognitive aspects of readiness to change attitude) are likely important mediators of the relationship between work setting changes and individual behavioral change. Porras and Robertson (1992) proposed that important link in their model, but did not examine it. Second, individual 
perceptions of the organizational context surrounding change, not just the actual context itself, should be examined. These include not only perceptions of work setting variables, but also perceptions about how well the organization supports individual change, and perceptions about how well the general membership of the organization is prepared for change. Although the OD literature focuses on the objective changes made in work setting variables as precursors of individual change (Porras \& Robertson, 1992), various bodies of literature (Berger \& Luckmann, 1967; Czarniawska-Joerges, 1992; Eisenberger et al., 1986; Schein, 1991; Weick, 1995) acknowledge the importance of the individual's subjective view of an organizational context and the changes that are occurring in this context. The authors of these studies posit that the subjective view is the critical influence on one's attitudes and subsequent behavior. Therefore, in models of organizational change, it might be important to conceptually and empirically distinguish objective work setting changes (i.e., what changes were actually made in work settings) from subjective work setting changes (i.e., what changes individuals perceived occurred in the work setting).

\section{Objective and subjective organizational context.}

Objective context reflects the work setting variables (and possible changes in them) actually in place in the organization. Karl Weick, in his book Sensemaking in Organization (1995), on the other hand, highlights the importance of social construction of organizational phenomena. He posits that "to talk about sense making is to talk about reality as an ongoing accomplishment that takes form when people make retrospective sense of the situations in which they find themselves and their creations" (Weick, 1995, p. 15). Furthermore, Czarniawska-Joerges (1992) defines organizations as ".. nets of collective action, undertaken in an effort to shape the world and human lives. The contents of the action are meanings and things (artifacts). One net of collective action is distinguishable from another by the kind of meanings and products socially attributed to a given organization." (p. 32) The social constructivist perspective infers that what people "know" as "reality" in their everyday lives represents the taken for granted view of the organization. "Knowledge" constitutes the fabric of meaning, without which no society [or organization] could exist (Berger \& Luckmann, 1967, p. 15), where the "basic assumptions and beliefs [are] shared by organization members" (Schein, 1991, p. 6). Thus, the objective aspects of an organization are not always those that are perceived by an individual. These concepts highlight the existence of objective and subjective levels of an organizational context. OD practitioners and researchers assume that what is done in the work setting to institute change is reflected in individuals' perceptions of these changes, but the objective and subjective may not always closely correspond with each other. Individuals perceive the context of the organization by attaching meaning to observations from their day-to-day dealings within the organization (Schein, 1991). For example, the level, quality and clarity of the message communicated by the change agents of a university while implementing a technology change might be perceived differently by different employees. On the other hand, we would expect that there would be some relationship between what has been done and what employees perceive has been done in the work settings. Therefore: 
Proposition 1: Objective measures of organizing arrangements regarding change in the work setting will be positively related to subjective perceptions of work settings regarding change.

\section{Perceived organizational support.}

The theory of perceived organizational support (Eisenberger et al., 1986) posits that employees tend to view actions by agents of the organization as actions of the organization itself (Levinson, 1965). The personification of the organization is assumed to represent an employee's view of who controls that individual's material and symbolic resources within the organization (Eisenberger et al., 1986). The theory suggests that through employee commitment and involvement, an employee develops global beliefs concerning the extent to which the organization values their contributions and cares about their well-being. In addition, the theory postulates that such effort-outcome expectancies would allow one to create a positive emotional bond with the organization and increase an employee's effort to meet the organization's goal (Eisenberger et al., 1986). Thus, perceived organizational support is a general perception concerning the degree to which the organization values employees' contributions and cares about their well-being, which results in greater employee affective commitment towards the organization and increases efforts made by individuals on its behalf. In the present research, it is suggested that when introducing ERP systems in organizations, perceived organizational support might help employees develop a higher state of readiness to adopt the technology.

The latest review of the perceived organizational support literature by Rhoades and Eisenberger (2002) yields 70 studies that support three major categories of antecedent variables that are positively related to perceived organizational support. The first category is fairness, which reflects available resources and their distribution among employees. Structural determinants of fairness represent the rules, procedures and policies concerning the decisions about change that will ultimately affect the employees (e.g., notice before implementation, accurate information, and employee input in the decision process). Fairness in resource allocation, on the other hand, includes the quality of interpersonal treatment in resource allocation to all employees. The second category of variables that is related to perceived organizational support is supervisor support, defined as the degree to which one's supervisor is perceived to value one's contributions and care for one's well-being. The last category of variables related to perceived organizational support is rewards and favorable job conditions that reflect the human resource practices within the organization that recognize an employee's contribution (i.e., pay, recognition, promotion, and training).

All of the above categories of antecedents of perceived organizational support seem similar to the work setting variables described by Porras and Robertson (1992). That is, if employees perceive that changes in organizational arrangements, social factors and technology are supportive of the change initiative, then employees' perceived organizational support might be enhanced. Therefore, we posit: 
Proposition 2: Perceptions of work settings will be positively related to perceptions of organizational support.

Rhoades and Eisenberger (2002) found in their review that employee perceived organizational support is positively related to favorable employee attitudes (job satisfaction and organizational commitment) and behaviors (lessened withdrawal behaviors). Therefore, if employees perceive that the organization is supportive of change initiatives, then their attitudes toward change should be more positive (i.e., they should experience greater readiness to change). Therefore, we posit:

Proposition 3: Perceptions of organizational support will be positively related to the components of individual readiness to change.

\section{Self-efficacy regarding change.}

Bandura (1977) states that self-efficacy reflects the belief of individuals that they have the capacity to attain desired goals within specific situations. Therefore, self-efficacy, as perceived by the individual, is a cognitive mechanism underlying behavioral change (Bandura, 1977; Cervone, 2000). Cervone (2000) states that despite one's belief about what causes "outcomes or the contingencies between responses and outcomes in the environment, [individuals] are unlikely to take action to control events if they doubt their own capacity to execute requisite behaviors" (p. 31). Decisions involving choice of activities are partly determined by judgments of personal efficacy (Bandura, 1997), therefore self-efficacy is viewed to have a central role in the study of behavior change. That is, individual readiness to change might be affected by employees' beliefs regarding their capacity to perform the new behaviors that the change requires.

Bandura's (1977) research, as well as subsequent research (Levesque et al., 1999; Wanberg \& Banas, 2000), support perceived self-efficacy as a cognitive mechanism essential to behavior change. Research supports self-efficacy as a predictor of future performance. Silver and colleagues (1995) found that self-efficacy, even in unsuccessful performances, positively influences future performance $(35 \%)$, as well as has a moderating effect on the relationship between performance and attributions. Through cognitive representation of future outcomes, individuals can generate current motivators of behaviors (Bandura, 1977). Therefore, theorists (Cervone, 2000; J. O. Prochaska \& DiClemente, 1994) propose that a rise in self-referent thinking should allow the individual to embrace change by adopting new behaviors. Developers of the Transtheoretical Model (TTM) described earlier found self-efficacy to positively predict movement across stages (J. O. Prochaska, DiClemente, Velicer, Ginpil, \& Norcross, 1985). That finding suggests that self-efficacy may have a direct effect on an individual's readiness to change. On the other hand, the perceived organizational support (POS) literature posits that by enhancing an individual's perceived competence, POS might heighten an employee's interest in his/her job (Rhoades \& Eisenberger, 2002). Therefore, perceived organizational support, compounded by self-efficacy, might increase an individual's readiness to change. Thus, we suggest self-efficacy will have a 
moderating effect on the relationship between perceived organizational support and the individual's readiness to change. Therefore:

Proposition 4: Self-efficacy will moderate the relationship between perceived organizational support and the components of individual readiness to change.

Perceived organizational membership readiness to change.

Eby and her colleagues emphasize that the importance of change must manifest itself throughout the organization. Characteristics of an organization must support and reinforce a climate conducive to change in order for change to be successful (Eby et al., 2000). Perceived organizational membership readiness is defined as the individual's belief that the organizational membership is or is not ready to undergo the change. That perception is derived from the perceived actions of the membership in the organization as well as factors related to environmental and structural components of organizational climate. Schneider and Bowen (1990; 1993) have found strong support for the importance of such variables in sustaining favorable climate perceptions, which embeds the message for change that the organization projects to its members (Armenakis et al., 1993). Members pick up clues about what is happening in the organization by way of work setting changes that tell them that the organization is ready for change including the perception that others in the organization are ready for change. Characteristics of the organization including its membership must support and reinforce the climate for change (Eby et al., 2000). The more those changes are perceived in work settings, the more employees might believe that the organization and its membership are ready for change. Therefore, we posit:

Proposition 5: Perceptions of work settings will be positively related to perceptions of membership readiness to change.

Furthermore, studies have also revealed that perceived organizational membership readiness significantly influences an individual's readiness to change (Eby et al., 2000; Rafferty \& Simons, 2001). Lastly, we theorize that:

Proposition 6: Perceptions of organizational membership readiness to change will be positively related to the components of individual readiness to change.

\section{Variables and Measures Discussion}

This paper examines the relationship between the context in an organization, both objective and as perceived by individuals, and an individual's readiness to adopt change. Although not clearly operationalized in reliable measures in the literature, we explore means to measures the prescribed antecedents to individual readiness to change outlined in the previous sections. 


\section{Objective Work Setting Variables.}

Objective context reflects the organization arrangements, social factors, and technology surrounding the implementation of change. Although they have been operationalized by Porras and Robertson (1992), no reliable and meaningful measures for these constructs have been cited in the literature. One limitation is in the nature of the data which often comes in the form of words rather than numbers (Miles \& Huberman, 1994). Answers to these items would come from key personnel interviews and content analysis of various sources of information distributed about the change across the organization (e.g., Newsletter, organization newspaper, change web site, memos and e-mails). It calls for a credible, dependable, and replicable means of measuring the context of change. Although defined as uncharted territory in the literature, it is a dimension of change rich in information that could offer significant insights on the qualitative nature of the context of change.

\section{Subjective Context of the Organization.}

Subjective context represents the individuals' perceptions of the work setting variables with regard to the change. Again no measures have risen from the literature since some (Agarwal, 2000) argue that situational influences are not separate constructs in and of themselves but embody complex combinations of managerial interventions, individual differences and social influences. Although the literature (Bandura, 1986; Davis, Bagozzi, \& Warshaw, 1989; Rogers, 1995) has recognized the importance of perceptions it provides very few insights on how to develop reliable measures in the context of change. Following Porras and Robertson's (1992) categorization of the objective context a list of perceptions of the objective context can be generated in an attempt to measure this dimension of the model (i.e., to test people's subjective evaluation of the context of change we could ask employees if they have received clear communication about the change). It would offer some insight on how perceptions of the objective context would possibly mediate how the organization is designed to implement change (at least on paper) and how employees perceive the support and readiness as they get ready to adopt the change.

\section{Perceived Organizational Support.}

Perceived organizational support mirrors an employee's global belief that the organization values their contributions and cares about their well being, creating a positive emotional bond to the organization, resulting in extra efforts. This variable can be assessed using eight items from Survey of Perceived Organizational Support instrument (Eisenberger, Cummings, Armeli, \& Lynch, 1997; Eisenberger et al., 1986; Rhoades \& Eisenberger, 2002). Eisenberger and his colleagues selected these eight items from a pool of 36 items that were found to load highly on the main factor and that seem applicable to a wide array of organizations (Eisenberger et al., 1997). The scale has a reported Cronbach's alpha of .90 . 


\section{Perceived Organizational Membership Readiness to Change.}

Perceived organizational membership readiness to change is defined as the individual's belief that the organization is or is not ready to undergo the change through the perceived actions of the membership in the organization. The variable can be measured using a nine item scale developed by Eby and colleagues (2000) which was subsequently validated (Rafferty \& Simons, 2001), and has a reported reliability alpha of .86 .

\section{Individual Readiness to Change.}

Individual readiness reflects an individual's beliefs, attitudes and behavioral intentions towards a change effort. It can be measured as a temporal construct, (i.e., stage of change), an attitudinal predisposition, and an attitudinal construct with three dimensions. The temporal construct, stages of change, characterizes an individual readiness to take action and can be assessed using a single item reflecting the work of Prochaska and colleagues (J. M. Prochaska, Levesque, Prochaska, Dewart, \& Wing, 2001; J. O. Prochaska \& DiClemente, 1984; J. O. Prochaska, DiClemente, \& Norcross, 1992). The second measure of individual readiness depicted as a predispositional characteristic reflecting the effort of Oreg (2003). The third measure is based on assessing the cognitive, affective and behavioral intentions associated with a change readiness attitude developed by Desplaces \& Beauvais (2004).

\section{Self-efficacy.}

Self-efficacy echoes the belief of individuals that they have the capacity to attain desired goals. As a generative capacity in which cognitive, social and behavioral subskills are organized in course of action to serve the change that is currently being undertaken, this construct has received substantial attention particularly in the adoption of new behavior literature. We propose to use a 14-item scale developed by Levesque and her colleagues (1999) in part because of its reported high reliability (Cronbach's alpha of .96).

\section{Conclusion}

This research sought to further our understanding of organizational change through individual behavioral change by focusing on the antecedents of individual behavior change, namely individual readiness to change. This comprehensive (although not exhaustive) approach to individual readiness to change and the study and its antecedents explore the link between the macro and micro levels of change, namely objective and subjective work settings, and proposing meaningful measures in an effort to link them to individual readiness to change. The model offers a potentially useful way to guide and evaluate individual readiness to change in its context. It echo Pettigrew and colleagues (2001) assertion that the context and action are inseparable and that the study of change regarding individual readiness must explore how contexts, content, and 
processes of change together with their interconnections over time influence individual readiness to change. Therefore, future research should examine the impact that organizing characteristics have on change efforts, including developing reliable and objective measures that are psychometrically sound of measuring the variables defined in our model.

In addition, future studies should seek to understand how contextual variables relate to individual change processes, such as self efficacy, motivation to change, and internal dispositional variables, such as tolerance for ambiguity, internal locus of control, dispositional construct of readiness to change. Further, group norms and organizational cultural values that support or discourage change need to be examined in terms of their effects on individual readiness to change attitudes in an effort to strive a balance between change and resistance to it (Leana \& Barry, 2000).

Finally, future work should test the full proposed model including testing the relationship between individual readiness to change and newly adopted behaviors to assess the role that individual readiness to change plays in determining newly adopted behaviors including the direct and indirect role of self efficacy on that relationship and the impact that the context of change has on an overall change effort.

\section{References}

Abrahamson, E. (2000). Change without pain. Harvard Business Review, 78(4), 75-79. Agarwal, R. (2000). Individual acceptance of information technologies. In R. W. Zmud (Ed.), Framing the domains of IT management: projecting the future through the past (pp. 85-104). Cincinnati, Ohio: Pinnaflex Education Resources, Inc.

Ajzen, I. (1984). Attitudes. In R. J. Corsini (Ed.), Wiley Encyclopedia of Psychology (Vol. 1, pp. 99-100). New York: Wiley.

Allport, G. W. (1967). Attitudes. In F. Martin (Ed.), Readings in Attitude Theory and Measurement (pp. 1-13). New York: JohnWiley \& Sons, Inc.

Armenakis, A. A., \& Bedeian, A. G. (1999). Organizational change: A review of theory and research in the 1990's. Journal of Management, 25(3), 293-315.

Armenakis, A. A., Harris, S. G., \& Mossholder, K. W. (1993). Creating readiness for organizational change. Human Relations (43), 681-703.

Bandura, A. (1977). Self-Efficacy: towards a unifying theory of behavior change. Psychological Review, 84, 191-215.

Bandura, A. (1986). Social Foundations of Thought and Action: A Social Cognitive Theory. Englewood Cliffs, NJ: Prentice Hall. 
Bandura, A. (1997). Self-Efficacy: the Exercise of Control. New York: W.H. Freeman. Berger, P. L., \& Luckmann, T. (1967). The social construction of reality: a treatise in the sociology of knowledge. New York: Doubleday.

Bernstein, W. M., \& Burke, W. W. (1989). Modeling organizational meaning systems. In R. W. Woodman \& W. A. Pasmore (Eds.), Research in organizational change and development (Vol. 3). Greenwich, CT: JAI Press.

Cervone, D. (2000). Thinking about self-efficacy. Behavior Modification, 24(1), 30-56.

Czarniawska-Joerges, B. (1992). Exploring complex organizations: a cultural perspective. Newbury Park, CA: Sage.

Davis, F. D., Bagozzi, R. P., \& Warshaw, P. R. (1989). User Acceptance Of Computer Technology: A Comparison Of Two theoretical models. Management Science, 35(8), 982-1002.

de Jager, P. (2001). Resistance to Change: a new view of an old problem. The Futurist, 35, 24-27.

Desplaces, D. E., \& Beauvais, L. L. (2004). Readiness to Change Attitude. Paper presented at the Academy of Management, Seattle, WA.

Eagly, A. H., \& Chaiken, S. (1993). The Psychology of Attitudes. Forth Worth: HBJ. Eby, L. T., Adams, D. M., Russell, J. E. A., \& Gaby, S. H. (2000). Perceptions of organizational readiness to change: Factors related to employee's reactions to the implementation of team selling. Human Relations, 53(3), 419-442.

Edwards, R. W., Jumper-Thurman, P., Plested, B. A., Oetting, E. R., \& Swanson, L. (2000). Community readiness: research to practice. Journal of Community Psychology, $\underline{28}(3), 291-307$.

Eisenberger, R., Cummings, J., Armeli, S., \& Lynch, P. (1997). Perceived organizational support, discretionary treatment, and job satisfaction. Journal of Applied Psychology, $\underline{82}(5), 812-820$.

Eisenberger, R., Huntington, R., Hutchison, S., \& Sowa, D. (1986). Perceived organizational support. Journal of Applied Psychology, 71(3), 500-507. Gleick, J. (1987). Chaos: making a new science. New York: Viking.

Huy, Q. N. (1999). Emotional capability, emotional intelligence, and radical change. Academy of Management Review, 24(2), 325-345.

Leana, C. R., \& Barry, B. (2000). Stability and change as simultaneous experiences in organizational life. Academy of Management Review, 25(4), 753-759. 
Levesque, D. A., Prochaska, J. M., \& Prochaska, J. O. (1999). Stages of change and integrated service delivery. Consulting Psychology Journal: Practice and Research, 51(4), 226-241.

Levinson, H. (1965). Reciprocation: the relationship between man and organization. Administrative Science Quarterly, 9, 372-378.

Lewin, R. (1951). Field theory in social science. New York: Harper and Row.

Miles, M. B., \& Huberman, A. M. (1994). Qualitative Data Analysis (2nd ed.). Newbury Park, CA: Sage.

Olson, J. M., \& Zanna, M. P. (1993). Attitudes and attitude change. Annual Review of Psychology, 44, 117-138.

Oreg, S. (2003). Resistance to change: developing an individual differences measure. Journal of Applied Psychology, 88(4), 680-693.

Pettigrew, A. M., Woodman, R. W., \& Cameron, K. S. (2001). Studying organizational change and development: challenges for future research. Academy of Management Journal, 44(4), 697-713.

Piderit, S. K. (2000). Rethinking resistance and recognizing ambivalence: A multidimensional view of attitudes toward an organizational change. Academy of Management Review, 25(4), 783-794.

Porras, J. I., \& Robertson, P. J. (1992). Organizational development: theory, practice, and research. In M. D. D. L. M. Hough (Ed.), Handbook of industrial and organizational psychology (2nd ed., Vol. 3, pp. 719-822). Palo Alto, CA: Consulting Psychologists Press, Inc.

Porter, L. W., \& Lawler, E. E. I. (1968). Managerial attitudes and performance. Homewood, IL: Irwin.

Prochaska, J. M., Levesque, D. A., Prochaska, J. O., Dewart, S. R., \& Wing, G. R. (2001). Mastering change: A core competency for employees. Brief Treatment and Crisis Intervention, 1(1), 7-15.

Prochaska, J. O., \& DiClemente, C. C. (1984). The Transtheoretical Approach: Crossing Traditional Boundaries of Therapy. Homewood, Ill: Dow Jones-Irwin.

Prochaska, J. O., \& DiClemente, C. C. (1994). The Transtheoretical approach: Crossing traditional boundaries of therapy. Malabar, FL: Krieger Publishing Company.

Prochaska, J. O., DiClemente, C. C., \& Norcross, J. C. (1992). In search of how people change: applications to addictive behaviors. American Psychologist, 47(9), 1102-1114. 
Prochaska, J. O., DiClemente, C. C., Velicer, W. F., Ginpil, S., \& Norcross, J. C. (1985). Predicting change in smoking status for self-changers. Addictive Behaviors, 10, 395406.

Rafferty, A. E., \& Simons, R. H. (2001). An empirical examination of the relationship between change readiness perceptions and types of change. Paper presented at the Academy of Management Meeting, Washington, D.C.

Rhoades, L., \& Eisenberger, R. (2002). Perceived organizational support: A review of the literature. Journal of Applied Psychology, 87(4), 698-714.

Rogers, E. M. (1995). Diffusion of innovation (Fourth ed.). New York, NY: The Free Press.

Schein, E. H. (1991). Organizational culture and leadership: a dynamic view. San Francisco: Jossey-Bass.

Schein, E. H. (1996). Kurt Lewin's change theory in the field and in the classroom: Notes towards a model of managed learning. Systems Practice, 9(1), 27-47.

Schneider, B. (1990). The climate for service: an application of the climate construct. In B. Schneider (Ed.), Organizational climate and culture (pp. 383-412). San Francisco, CA: Jossey-Bass.

Schneider, B., \& Bowen, D. E. (1993). The service organization: human resources management is crucial. Organizational Dynamics, 21(4), 39-52.

Silver, W. S., Mitchell, T. R., \& Gist, M. E. (1995). Responses to successful and unsuccessful performance: the moderating effect of self-efficacy on the relationship between performance and attribution. Organizational Behavior and Human Decision Processes, 62(3), 286-299.

Van de Ven, A. H., \& Poole, M. S. (2002). Field research methods. In J. A. C. Baum (Ed.), Companion to organizations (pp. 867-888). Oxford: Blackwell Publishers. Vroom, V. H. (1964). Work and motivation. New York: Wiley.

Wanberg, C. R., \& Banas, J. T. (2000). Predictors and outcomes of openness to changes in a reorganizing workplace. Journal of Applied Psychology, 85(1), 132-142. Weick, K. E. (1995). Sensemaking in organizations. Thousand Oaks: Sage Publications. 